\title{
Attitudes of students of psychology departments in Sudanese universities towards people with disabilities (Psychology male and female students in universities in the state of Gezira as a model)
}

\author{
Hayat Abdel Rahim Mohamed Amin ${ }^{1}$, Makki Babiker Saeed Deiwa ${ }^{2}$, \\ Al-Fateh Mustafa Suleiman Al-Kinani ${ }^{3}$ \\ ${ }^{1} \mathrm{PhD}$ student, Faculty of Education, University of Gezira, Sudan \\ ${ }^{2,3}$ Associate Professor of Educational Psychology, College of Education, University of Gezira, \\ Sudan \\ 22makkideiwa@gmail.com
}




\title{
Attitudes of students of psychology departments in Sudanese universities towards people with disabilities (Psychology male and female students in universities in the state of Gezira as a model)
}

\section{Hayat Abdel Rahim Mohamed Amin ${ }^{1}$, Makki Babiker Saeed Deiwa ${ }^{* 2}$, Al-Fateh Mustafa Suleiman Al-Kinani ${ }^{3}$}

\author{
${ }^{1} \mathrm{PhD}$ student, Faculty of Education, University of Gezira, Sudan \\ ${ }^{2,3}$ Associate Professor of Educational Psychology, College of Education, University of Gezira, \\ Sudan \\ 2makkideiwa@gmail.com
}

\author{
Received: 20-8-2021 Revised: 29-5-2021 Accepted: 1-9-2021 DOI: https://doi.org/10.31559/CCSE2021.3.1.2
}

\section{Abstract:}

The level of disability is determined by the environment's ability to create legal conditions, and the concept of disability has carried several connotations throughout history and cultures that have been affected by the moral character sometimes, medical, educational, and rehabilitative at other times, and the material and social that enables the individual to participate, interact and integrate. The study aimed to identify the trends of the departments of psychology Towards people with disabilities, and the research community consisted of male and female students from the psychology departments of universities (Al-Jazeera, Al-Batana, and the Holy Qur'an), from whom the researcher chose (313) male and female students by the stratified random method to represent the study community. For the study, the data were analyzed by the Statistical Package for Social Sciences (SPSS) program. The study found several findings, including: the attitudes of students of psychology departments in Sudanese universities towards people with disabilities are positive, there are no differences in the attitudes of psychology students towards people with disabilities according to the gender variable, and there are no differences in the attitudes of psychology students towards people with disabilities according to the Al-Jakea variable, The study recommends the importance of raising the practical training quota for psychology students in Sudanese universities.

Keywords: Psychology; Disabilities; Universities; Students.

\footnotetext{
* Corresponding author

Makki Babiker Saeed Deiwa

Associate Professor of Educational Psychology, College of Education, University of Gezira, Sudan

E-mail: makkideiwa@gmail.com
} 
International Journal of Childhood, Counselling, \& Special Education (CCSE), Volume3, Issue1, Sept: 2021, pp.20-31

\section{Introduction}

And we find that ordinary individuals deal with the disabled in many Arab societies on the basis that they are different from other people, regardless of the nature of their attitudes towards them, whether positive or negative, so much that the vocabulary that is called or called upon by the disabled, including blind, handicapped, demented to Other names, which contributed to the formation of a negative image of themselves, and even of others around them (Al-Jarrah, 2005, 84).

\section{The Study Problem:}

The university is an essential tributary to society, with what it needs of qualified individuals to occupy jobs in its various forms, public and private, and since ordinary university students, including them and the disabled, are the tool for change and construction in any society, and since the university community depends mainly on students' consensus, this makes it imperative for ordinary students to deal directly With their peers of disabled students in various areas of life away from bullying and sarcasm, which negatively affects the personality of the disabled, and students may vary in the degree of their attitudes towards the disabled, which negatively affects the effectiveness of dealing and communication between ordinary and disabled students, which naturally depends on the quality of attitudes towards each other Somewhere the negative view of ordinary people prevents them from facilitating the process of social and academic integration among them. Therefore, the researcher believes that it is necessary to study the attitudes of students of psychology departments in Sudanese universities (students of psychology departments in Gezira state universities as an example.
The problem of the current study lies in the main question:

What is the characteristic of the attitudes of students of psychology departments in Sudanese universities, male and female psychology students in universities in Gezira State, towards people with disabilities?

The following sub-questions are derived from the main question:

1. What is the relationship between the attitudes of male and female students of psychology departments in the universities in the state of Gezira and the academic level?

2. Are there statistically significant differences in the attitudes of male and female students of the psychology departments in the universities in the state of Al-Jazirah that are due to the university?

\section{The Importance of Study:}

The importance of the study lies in the following:

1. From the scientific point of view: This study acquires its importance from the nature of the topic it deals with in the research, which is the attitudes of students of psychology departments in Sudanese universities (students and students of psychology in universities in Gezira state as a model) towards the disabled, because revealing those trends and determining their quality, and the differences in them between the different groups From people, it is a basis for the efforts that can be taken, whether at the general social or educational level, to prepare educational, guidance and educational programs organized to support positive attitudes towards the disabled and modify negative attitudes.

2. From a practical point of view: the study derives part of its importance from the nature of the sample used, as 
International Journal of Childhood, Counselling, \& Special Education (CCSE), Volume3, Issue1, Sept: 2021, pp.20-31

it is supposed to work in the future in different service and development sectors such as education, which may shed light on the nature of the relationship between their university studies and the extent of integration of psychological aspects with cognitive aspects of what they receive their curricula On the one hand, and the quality of their attitudes towards the disabled on the other, and the consequent steps taken to make them more accepting of the disabled, more enthusiastic and keen on the services they provide them.

\section{Objectives of the Study:}

The current study aims to:

1. Knowing the attitudes of male and female students of psychology departments in the universities in the state of Gezira towards people with disabilities and knowing the factors that contribute to the formation and development of these trends and the development of how to deal with people with disabilities.

2. Knowing how to develop and develop the concept of these trends towards people with disabilities to deal with them, as they are the most in contact with them and with their education and development so that they can deal in society with a high morale and enter them at a steady pace.

\section{Study Assignments:}

1. The attitudes of male and female psychology students in universities in Al-Jazirah State are positive.

2. There are statistically significant differences in the attitudes of male and female psychology students in universities in the state of Al-Jazirah due to the academic level.

3. There are statistically significant differences in the attitudes of male and female psychology students in universities in the state of Al-Jazirah that are attributed to the university.

The Limits of the Study:

Objective limits: Attitudes of students of psychology departments in Sudanese universities (students of psychology in universities in Gezira state.

Time limits: the study was conducted in the period from (March-August 2020 AD). Spatial limits: The study includes students of psychology departments in universities in the state of Al-Jazirah (Al-Jazirah - AlBatana - Al-Ahlia).

\section{Terminology of study:}

Attitudes: Attitude is an acquired willingness saturated with emotion that determines the individual's behavior towards situations, topics, and people that he deals with in the surrounding environment, either by accepting or rejecting them (Othman, 2009, 72).

As for the procedural definition of trends in the study, it means the opinions, ideas, beliefs, perceptions, and feelings that the student holds towards the disabled, and it is measured procedurally through the student's performance on the study tool, in which the high degree indicates the positive of these trends, while the low degree indicates their negative.

\section{People with Disabilities:}

Persons with disabilities are those people who differ in one way or another from people who are specifically considered normal by society. When we talk about people with disabilities, we are talking about individuals whose physical, mental, or behavioral performance differs fundamentally from the performance of their ordinary peers (AlRahhal, 2005, 67).

\section{Theoretical Framework of the Study}

Attitudes There is importance of trends in human life in general and in the 
educational process, as it is a prior preparation of the individual towards something. The individual towards others and ideas facilitate us the process of predicting expected behaviors towards them. The study of psychological trends has emerged since the late twentieth century, where it has received endless attention from most researchers in social psychology and education in particular, where the study of psychological trends of individuals plays a role in explaining their current behavior and predicting their future behavior towards events, topics and phenomena. It is a reflection of his psychological trends that he acquires from the means of normalization and social communication, such as the family, school and society (Abdul Halim, 2004). About the self and identification and help him to make successful psychological decisions without hesitation (Al-Juhaimi) (2007). Attitudes are among the underlying factors that drive behavior and motivate him in a specific direction to achieve the individual's needs. Studying the individual's trends helps predict his different behaviors and responses to the stimuli that he is exposed to in his daily life. (documentation)

The concept of direction: Suhair Kamel (2000) mentions that the trends are either negative or positive depending on the response issued by them (compliance aversion), or the trends may be qualitative or general, strong or weak. There are many concepts of psychological trends and we will present some of them as follows: The Porte defines 1969 (Alport) Attitude is a state of mental and nervous disposition that is organized by experience and has a general dynamic effect and directs the individual's responses to different topics and situations, as Borng and Langfelt (1979) defined the attitude as the mental state that directs the responses of the individual and Triandis defined the trend It is an idea saturated with emotion that tends to move behavior towards a specific category of situations, and he sees that the trend has three components, a mental component, an emotional component and a behavioral component, and Suhair Kamel (2000) believes that the trend is an acquired readiness imbued with emotion that determines the individual's behavior towards situations, topics and people he deals with. In the surrounding environment, either by accepting it or rejecting it, as Hamed Abdel Salam Zahran (2000) in Al-Faki (2015) defines the trend as a hypothetical formation, or a latent or intermediate variable (which lies between the stimulus and the Response (which is a psychological readiness, or an educated nervous mental preparation for the positive or negative response (acceptance or rejection) towards people, things, subjects or controversial situations in the environment that provokes this response (Al-Fiqi et al., 231,230, 2015) components of the trend: the trend consists of: Three elements are:

1. The cognitive component: which is acquired through the environment surrounding the individual and the degree of his culture at the time of his education. Some people call it the cognitive mental component, and it includes the individual's beliefs about the subject of direction.

2. The emotional component: where the trend is affected by psychological reinforcement and support, which is represented in the degree of relief or constriction that accrues to the individual during his interaction with different situations, and some call it the emotional component and includes emotions and feelings such as anger or fear, and a feeling of joy ... etc. And the associated activities of the sympathetic nervous system.

3. The behavioral component: which represents the external destination for it, which reflects the individual's values 
International Journal of Childhood, Counselling, \& Special Education (CCSE), Volume3, Issue1, Sept: 2021, pp.20-31

and the trends and expectations of others. It is also called the propensity component and is represented in the individual's behavioral responses or inclination, such as (the intention to perform a specific behavior about the trend. Those in charge of raising children should pay attention to these three components, and that the child acquires the desired positive attitudes that are supported and supported to build an integrated personality for him and that it is known to educators that the direction of the individual Towards a specific subject subject to change and modification through acquiring new information, as well as directly practicing experiences (Mansour, Ali, 2001).

\section{Previous Studies:}

- Al-Suwaiti study, Abdel Nasser (2016): Under the title Attitudes and opinions of teachers and administrators in public education towards the inclusion of extraordinary children in ordinary primary schools in the Hebron region, the study aimed to know the attitudes and opinions of primary school teachers and administrators about the inclusion of extraordinary children in public primary schools In the South Hebron Education Directorate, where the study sample consisted of (110) teachers and administrators, the study used the questionnaire tool, which included (26) items distributed over three dimensions. Teachers toward inclusion in general were positive, and that there were no differences between teachers and administrators toward integrating people with disabilities with ordinary students. The results also indicated that there were no differences attributable to the gender of the teacher or administrator with regard to inclusion. The results also indicated that there were no differences due to years of experience, as it was found the more years of experience, the greater the acceptance process.

- Zito study (zito, 1997): The study aimed to know the effectiveness of the integration program for children with simple mental disabilities in the regular primary school, where two classes of mentally handicapped children were merged in the form of special classes attached to the regular school, where the performance of normal and disabled children was observed before and after the procedure In the study, the results indicated the positive attitudes of ordinary students towards mentally handicapped students, represented in avoiding verbal aggression. The results also showed an increasing growth in social interaction for mentally handicapped students compared to children who did not join the integration programs and remained in special education day centers.

- The study of Abdul Ghafour (1996): The study aimed to know the opinions and attitudes of primary school teachers and administrators about the integration of the unusual child at that stage in the State of Kuwait. Two of them are for males and the other for girls, where the study used a questionnaire tool whose phrases were distributed over three areas. The study concluded that integration changes new educational trends that serve unusual children, as it provides them with opportunities for positive interaction with ordinary children within the school, and that there is a lack of Acceptance of inclusion in general by the sample members, and the results also showed that the motor and visual disabilities obtained a better degree of acceptance than the auditory 
and mental disabilities towards their inclusion in the regular school, in addition to the mild and medium disabilities that were accepted towards their inclusion in the regular school in a way that exceeds the disabilities of the same degree. The degree of depth, and that there are obstacles that prevent the application or acceptance of integration in the regular school in Kuwait, which are arranged according to the depth of this problem: Medical services The results showed that there were statistically significant differences, some at the level of 0.05 and others at the level of 0.01 with regard to gender, occupation, and those who had previously dealt with the disabled towards inclusion, where It was found that male administrators and those who have previously dealt with a disabled person are more accepting of inclusion than female teachers and teachers who have never dealt with a disabled person.

- The study of Sasana and Ventetta (2006): entitled Attitudes of regular and special education teachers towards school integration for students with special needs. Furthermore, the study aims to reveal potential differences in teachers' attitudes when it comes to different disabilities and when issues such as the best time to integrate and which area is most beneficial for inclusion students are raised. It was completed Survey of a total of 377 teachers in Greece. The results showed that although both regular and special education teachers had neutral attitudes towards school inclusion, regular education teachers were more positive towards inclusion than their colleagues in special education. Moreover, younger and less experienced teachers were more positive towards inclusion in the school, while there were no differences between male and female teachers' attitudes. Regarding the best time to start school inclusion, teachers' opinions differed only on a few options, with regular education teachers being more positive towards inclusion than special education teachers. Regarding the area most beneficial to students in the case of inclusion, again, the two groups of teachers differed in a few areas, with special education teachers realizing only the social benefit of inclusion.

\section{Study Approach:}

Based on the nature of this study and the goals it seeks to achieve, the researcher relied in conducting this study on the descriptive-analytical approach, due to its relevance to the objectives of the study. An accurate description of it qualitatively and quantitatively" (Osman, 2009, 84).

\section{Study Community:}

The study population consists of male and female students of psychology departments in Sudanese universities in the state of Gezira, where the following universities are in the state:

- University of Gezira

- Butana University

- Ahlia University

- And their number is (726) male and female students.

\section{Study Tools:}

To achieve the objectives of the study and answer its questions, the researcher built the study tool, which is the questionnaire, using the Attitude Scale towards the Disabled prepared by AlAhrouni and Farraj (1999). Al-Hajj, Mahasin (2014), Al-Harouni and Faraj study (1999), Al-Jarrah and Al-Bataineh study (2005), Al-Rahhal study (2005), the study of difficulties, Mutasim (2016), and the theoretical framework; To benefit from them in writing and drafting the 
International Journal of Childhood, Counselling, \& Special Education (CCSE), Volume3, Issue1, Sept: 2021, pp.20-31

paragraphs of the questionnaire, as well as the advice of experts in this field. The tool was built according to the following steps: The tool included two parts as follows:

The first part: included the basic primary data of the examinees, which are related to The Study Variables:

- Universities

- Type.

- Academic specialization.

- Academic level.

- Housing|(rural-city).

- (GPA).

As for the second part: the questionnaire consists of 36 paragraphs.

Resolution correction method:

The questionnaire was graded in a gradual manner (Likart quintuple) as follows:

- Strongly agree 5

- I agree 4

- Neutral 3

- I don't agree 2

- Strongly disagree 1

Validity of the tool:

Apparent honesty (the sincerity of the arbitrators):

This type of honesty was achieved through the procedures followed by the researcher in constructing the questionnaire, preparing its paragraphs, the extent to which these paragraphs represented the objectives of the questionnaire, and the validity of the linguistic formulation. His observations and amendments to the questionnaire and its paragraphs, and it also modified its directives, and then the study tool was presented to a number of specialized arbitrators in universities and educational institutions, and a group of expert arbitrators in educational and psychology disciplines, to review and scrutinize its paragraphs to determine the appropriateness of each paragraph, and the extent to which it belongs to the dimension its own, its linguistic integrity, the integrity of the wording, and the suggestion of amendments, if necessary, by deletion.

\section{Presentation and Discussion of the Results of the Study}

Results related to the main question: The question stated the following: What is the characteristic of the attitudes of male and female students of psychology departments in Sudanese universities in Gezira State towards people with disabilities?

To answer this question, the percentages, arithmetic averages, standard deviation, and arithmetic cumulative mean for all paragraphs of the questionnaire were first calculated to reveal the characteristic of the attitudes of male and female students of psychology departments in Sudanese universities in Gezira state towards people with disabilities, as shown in Table No. (1) below.

Table (1): Arithmetic averages and standard deviations of the answers of the study sample on the trait of attitudes of male and female students of psychology departments in Sudanese universities in Gezira state towards people with disabilities

\begin{tabular}{cccc}
\hline Trait of Attitudes & Mean & Standard Deviation & Result \\
\hline Total Sub of Responses & 3.74 & 0.5478 & $\begin{array}{c}\text { Strong Positive } \\
\text { Attitudes }\end{array}$
\end{tabular}

From Table No. (1) above, we find that:

A large percentage of respondents strongly agree that male and female students are ready to provide assistance to the disabled, and they are happy to share their hobbies with the disabled, and the disabled have interests and hobbies just 
International Journal of Childhood, Counselling, \& Special Education (CCSE), Volume3, Issue1, Sept: 2021, pp.20-31

like everyone else, and the disabled can practice useful work, and welcome the establishment of social relations with the disabled with arithmetic averages of (4.49, $4.42,4.28,4.22,4.22,4.21$ ) respectively

A very large percentage of respondents agree that the disabled should not feel inferior, and treat the disabled as normal, and the disability does not prevent the disabled from excelling, and the death of the disabled cannot be the solution to his problems, and the disabled tastes beauty like ordinary people, and the injury of the individual with any disability does not reduce People respect him, and the disabled should not be isolated from society, and the disabled do not constitute a heavy burden on their societies. Jobs are just like ordinary people, and the disabled can be a useful citizen. Educating the disabled is not a waste of time and effort. I like to appear with the disabled in front of people. The disabled person must be approached because he is a non-dangerous person. A party that brings ridicule, and the disabled is not one of the reasons for the backwardness of their societies, and allocating places for the disabled in the means of transportation is not a robbery of the rights of others. I accept the authentication of the disabled, with averages of $(4.13,4.03,3.94,3.84,3.83$, $3.81,3.79,3.75,3.75,3.73,3.72,3.71$, $3.70,3.69,3.66,3.66,3.62,3.61,3.61$, $3.57,3.55,3.53,3.53,3.45)$ respectively.

A large proportion of respondents agree to some extent or neutrally that it is not impossible for a disabled person to form a family, and the disabled should not go to their own clubs away from public clubs, and the capabilities of the disabled are much less than the ordinary in all cases, and the disabled are suitable for leadership positions, and they can I married a disabled man, despite my family's opposition, with arithmetic averages of $(3.34,3.25,3.23$, $3.17,2.96)$, respectively.

The above statements indicate moderate tendencies towards the acceptance of the disabled in taking individual responsibility, such as marriage and driving, despite the differences in disabilities and the degree of ability to bear responsibility. disabled, and the researcher believes that the average in our Sudanese society is the marriage of the disabled to each other more than the marriage of the ordinary to the disabled.

\section{Results related to the second hypothesis:}

Are there statistically significant differences in the attitudes of male and female students of psychology departments in the universities in the state of Gezira due to the university (Al-Jazirah, Al-Batana, AlAhlia)?.

To answer this hypothesis, the ANOVA test was calculated to identify the extent of the presence of statistically significant differences in the attitudes of male and female students of psychology departments in the universities in the state of Al-Jazirah attributable to the university (Gezira, Al-Batana, Al-Ahlia)), as shown in Table (2) below.

Table (2): shows the ANOVA test to identify the extent to which there are statistically significant differences in the attitudes of male and female students of psychology departments in universities in the state of Al-Jazirah attributable to the university

\begin{tabular}{|c|c|c|c|c|c|}
\hline $\begin{array}{l}\text { Contrast } \\
\text { Source }\end{array}$ & Sum of squares & $\begin{array}{l}\text { Degree of } \\
\text { Freedom }\end{array}$ & $\begin{array}{l}\text { Square of } \\
\text { Averages }\end{array}$ & P value of & $\begin{array}{l}\text { Significance } \\
\text { level }\end{array}$ \\
\hline $\begin{array}{l}\text { Between } \\
\text { groups }\end{array}$ & 70.24 & 2 & 35.12 & 207.99 & Significant \\
\hline Within Groups & 52.34 & 310 & 0.17 & & \\
\hline Amin & Amin & Amin & & & \\
\hline
\end{tabular}


International Journal of Childhood, Counselling, \& Special Education (CCSE), Volume3, Issue1, Sept: 2021, pp.20-31

It is clear from the above table that there are statistically significant differences at the level of 0.05 in the attitudes of male and female students of psychology departments in the universities in the state of Al-Jazirah that are attributed to the university.

Table (3): Scheffe table showing the source of the variance in a one-way university factor analysis of variance.

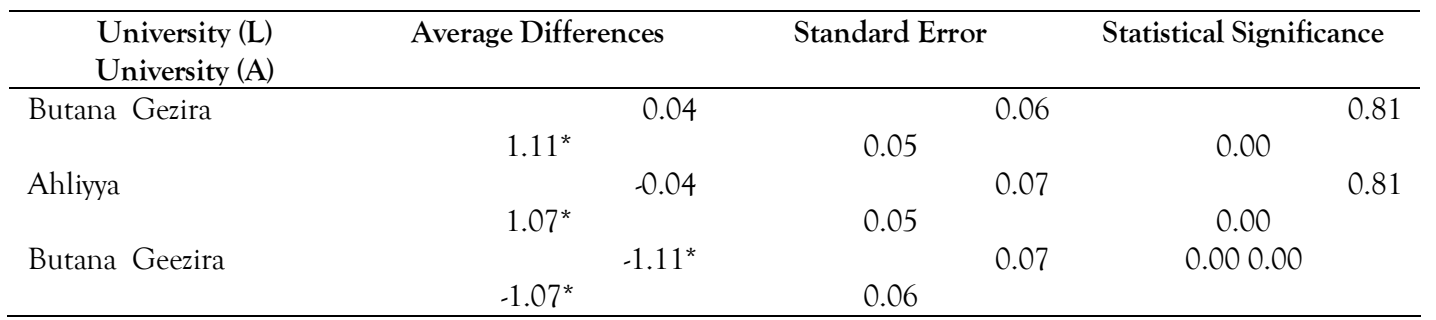

From Table No. (3) it is clear the differences between the opinions of male and female students according to the university. By comparing the University of Gezira with the Universities of Butana and Al-Ahlia, the differences were in favor of the Ahlia University, while comparing the University of Butana with the Universities of Gezira and Al-Ahlia was also in favor of the Ahlia University, while comparing the Ahlia University with the Universities of Gezira and Al-Butana was in favor of the two universities. Accordingly, we say that there are statistically significant differences in the opinions of male and female students attributable to the university.

The result of the hypothesis indicates that there are differences in the attitudes of male and female students according to the university. By comparing the University of Gezira with the Universities of Al-Butana and Al-Ahlia, the differences were in favor of the Ahlia University, while comparing Al-Butana University with the Universities of Gezira and Al-Ahlia was also in favor of the Ahlia University. As for comparing the Ahlia University with the Universities of Al-Jazirah and Al-Butana, it was in favor of the two universities, and accordingly we say There are statistically significant differences in the opinions of male and female students attributable to the university.
Accordingly, the hypothesis of the study is accepted, which says that there are statistically significant differences in the attitudes of male and female psychology students in universities in the state of Gezira that are attributed to the university. Where two classes of mentally handicapped children were merged in the form of special classes attached to the regular school, where the performance of ordinary and handicapped children was observed before and after conducting the study, and the results indicated the positive attitudes of ordinary students towards mentally handicapped students represented in staying away from verbal aggression, but the results also showed Increasing growth in the social interaction of mentally handicapped students compared with children who did not join the integration programs in the unintegrated special education day centers. It agrees with the Al-Soub study (2016) on the effect of teaching a course on rehabilitation of people with special needs in improving students' attitudes towards people with disabilities among a sample of students in the Faculty of Sports Sciences, where the results showed that there is an improvement in students' attitudes towards people with special needs after their study of a course on rehabilitation of people with special needs. The statistical 
International Journal of Childhood, Counselling, \& Special Education (CCSE), Volume3, Issue1, Sept: 2021, pp.20-31

differences indicate that the presence of student guidance programs improves students' attitudes towards persons with disabilities, and student activities may help in acceptance and improvement of attitudes towards persons with disabilities.

\section{Results related to the third question:}

The hypothesis states the following: Are there Statistically significant differences in the attitudes of male and female students of psychology departments in universities in the state of Al-Jazira due to gender (male-student)?

To answer this hypothesis, an independent sample test was calculated to identify the extent of the presence of statistically significant differences in the attitudes of male and female students of psychology departments in universities in the state of Gezira due to gender (male-student), as shown in Table No. (4) below.

Table (4): illustrates the T-test to identify the extent to which there are statistically significant differences in the attitudes of male and female students of psychology departments due to gender

\begin{tabular}{|c|c|c|c|c|c|c|}
\hline Gender & & Man & $\begin{array}{l}\text { Degree of } \\
\text { Freedom }\end{array}$ & St. Dev & T. Test V & Significance level \\
\hline Male & 58 & 3.44 & 2 & 0.65 & -4.11 & \\
\hline Female & 255 & 3.81 & 311 & 0.60 & & Significant \\
\hline Total & 313 & & 313 & & & \\
\hline
\end{tabular}

It is clear from the previous table No. (4) that there are statistically significant differences at the level (0.05) in the attitudes of male and female students of psychology departments in the universities in Gezira State due to gender (malestudent), and in favor of female students.

Accordingly, the third hypothesis is accepted, which says: There are statistically significant differences in the attitudes of male and female students of psychology in universities in the state of Gezira due to the gender (student - student).

The result showed that there were statistically significant differences at the level (0.05) in the attitudes of male and female students of psychology departments in the universities in the state of Al-Jazirah due to gender (student - female), and in favor of female students. On the third question that says: Are there statistically significant differences in the attitudes of male and female students of psychology departments in universities in the state of Gezira due to gender (male-student)?

Accordingly, the third hypothesis is accepted, which says: There are statistically significant differences in the attitudes of male and female psychology students in the universities in the state of Al-Jazira due to gender (male-student). The following variables: specialization, gender, and relationship with the disabled. The results of the study revealed that there are no statistically significant differences between males and females, and that females' attitudes are more positive than males' attitudes toward persons with disabilities.

This result differs with the study of difficulties (2016), the results of which found that there is not statistically significant above in the attitudes of students towards the disabled due to the variables of gender and academic achievement. Disabilities accepted in public schools are light and simple disabilities, and that teachers' attitudes towards inclusion in general were positive, and that there are no differences attributed to the gender of the teacher. The study also showed that there were no statistically significant differences in the attitudes of nursing students in Jordanian universities towards the disabled due to the gender 
International Journal of Childhood, Counselling, \& Special Education (CCSE), Volume3, Issue1, Sept: 2021, pp.20-31

variable. The study of Abdel Ghafour (1996): which aimed to know the opinions and attitudes of primary school teachers and administrators about the inclusion of the unusual child at that stage in The State of Kuwait, and the study found statistically significant differences, some at the level of 0.05 and others at the level of 0.01 with regard to gender, occupation and those who had previously dealt with a disabled person towards inclusion, as it was found that administrative males and those who previously dealt with a disabled person are more accepting of inclusion than females and teachers who have never dealt with the disabled, and it also agrees with the study of Rahal (2005), the results of which showed that females' attitudes are more positive than males' attitudes towards persons with disabilities.

\section{Study conclusion}

\section{The most important results:}

- The attitudes of students of psychology departments in universities in the state of Gezira towards the disabled are positive.

- There are no statistically significant differences in the attitudes of students towards the disabled, attributable to the university.

- There are no statistically significant differences in the students' attitudes towards the disabled due to gender (male-female).

\section{Recommendations:}

- Awareness of society with the psychology of the disabled and the need to accept them, as they are an important category of rights and duties as well as others.

- Designing and publishing indicative programs for families of persons with disabilities and for students in different educational stages about persons with disabilities and their different needs and the need to accept them.

- Disseminate programs for the full integration of the disabled with ordinary students in the various stages of study, to increase social interaction and build relationships based on respect and equality between the disabled and the rest of the community.

\section{Suggestions:}

- Based on the results, the researcher suggests conducting the following future studies:

- Studying the attitude of general education students towards the disabled, as they form early trends towards them in universities in the future.

- Designing guidance programs for students with disabilities and their families upon entering the university to measure the degree of interaction and acceptance of others and the extent of its impact on university students' attitudes towards them.

\section{References}

Al-Daghish, Tariq (2003). Attitudes towards the handicapped among students of special education in the College of Education. Taiz Research Journal, Arts and Humanities Series, Aden, No. (3).

Al-Harouni, Mustafa and Farraj, and Human (1999). Attitudes of university students towards the disabled and the effectiveness of a program in their development. Journal of Psychology, Cairo, 52: 148-130.

Al-Jarrah, Abdel-Nasser \& Batayneh, Osama (2005). Attitudes of Yarmouk University students towards the disabled and their relationship to some variables. Yarmouk Research. Humanities and Social Sciences Series. 21 (3A): 459-480. 
International Journal of Childhood, Counselling, \& Special Education (CCSE), Volume3, Issue1, Sept: 2021, pp.20-31

Al-Kinani, Reem (2009). The effectiveness of a proposed training program to develop the attitudes of nursing students in Jordanian universities and its impact on developing their communication skills. Unpublished master's thesis, Amman Arab University for Graduate Studies.

Al-Soub, Mutasim Abdel-Wahab (2016). The effect of teaching a course on rehabilitation for people with special needs in improving attitudes towards the disabled. Journal of the College of Education, Al-Azhar University, Issue: (168 Part Three).

Adas, Abdel Rahman Watawq, Mohieldin (2005). Introduction to Psychology, sixth edition. Amman: Dar Al-Fikr for printing, publishing and distribution.

Al-Ruwaili, Mada Allah (2007). Teachers' attitudes towards the inclusion of children with physical disabilities in public schools in the north of the Kingdom of Saudi Arabia. Unpublished master's thesis, Yarmouk University.
Bakhsh, princess (2000). The effectiveness of a counseling program to modify the attitudes of ordinary students towards integrating the mentally retarded with them in school and its impact on the adaptive behavior of mentally retarded students. The Educational Journal, Jaber AlAhmad Central Library.

Othman, Ibrahim Othman Hassan (2009). Scientific Research Methods in Education. Sudan Open University Publications.

Rahal, Dargham (2005). A study of the attitudes of some faculties of Al-Baath University students towards the disabled and their relationship to some variables. AlBaath University Journal, 27 (7): 238-213. Journal of the College of Education, AlAzhar University, Issue: (168 Part Three) April 2016.

Susana Padeliadu \&Venetta Lampropoulou (2006). Attitudes of special and regular education teachers towards school integration. Pages 173-183 | published online. 